\title{
Estimating the theoretical energy required to dry rice
}

\author{
Maria A. Billiris ${ }^{a}$, Terry J. Siebenmorgen ${ }^{a, *}$, Andy Mauromoustakos ${ }^{b}$ \\ a Department of Food Science, University of Arkansas, Fayetteville, AR 72704, USA \\ ${ }^{\mathrm{b}}$ Agricultural Statistics Lab., University of Arkansas, Fayetteville, AR 72701, USA
}

\section{A R T I C L E I N F O}

Article history:

Received 2 March 2011

Received in revised form 9 June 2011

Accepted 11 June 2011

Available online 23 June 2011

\section{Keywords:}

Heat of desorption

Desorption isotherms

Clausius-Clapeyron equation

\begin{abstract}
A B S T R A C T
The total heat of desorption of rice $\left(Q_{t}\right)$ was determined for several rice types as a function of moisture content (MC), and kernel temperature, using a semi-theoretical approach in which desorption isotherms were used in conjunction with the Clausius-Clapeyron equation. $Q_{t}$ decreased exponentially as MC increased, decreasing sharply for MCs above 15\% and approaching the latent heat of vaporization of free water at MCs around $20 \%$. $Q_{t}$ of parboiled rice at $12.5 \%$ MC was significantly less than that of nonparboiled lots. $Q_{t}$ of medium-grain "Jupiter" was significantly greater than that of long-grains at $12.5 \%$ MC. Equations that predict the energy required to dry a unit mass of rice from an initial MC to a final MC were derived.
\end{abstract}

(c) 2011 Elsevier Ltd. All rights reserved.

\section{Introduction}

In order to maximize field yield and quality, rice is typically harvested at MCs greater than the level deemed safe for long-term storage, which is often taken to be around $13 \%$ (Howell and Cogburn, 2004). To preserve its quality, rice should be thus dried to this safe level (Siebenmorgen and Meullenet, 2004).

Verma (1994) stated that the United States consumes 15 million barrels of crude oil per year for drying grains, making grain drying operations a major source of energy consumption. Kasmaprapruet et al. (2009) reported that drying was the most energy-consumptive unit operation in rice processing, accounting for $55 \%$ of the total energy consumed for production and processing of rice.

The energy required to dry grains under ideal conditions varies from 2500 to $2670 \mathrm{~kJ} / \mathrm{kg}$ water depending on the drying temperature $(T)$ (Fluck and Baird, 1980). However, Gunasekaran and Thompson (1986) stated that drying of crops actually requires from 3000 to $8000 \mathrm{~kJ} / \mathrm{kg}$ water. Therefore, the efficiency of a drying process depends on how drying is performed. Considering the ongoing interest in reducing energy requirements and the importance of the rice crop in the United States and globally, it is timely to investigate means of improving rice drying efficiency.

The first step in quantifying the performance of a rice drying process is to calculate the theoretical energy required to remove water from rice. The energy required for drying foodstuffs mainly comprises the thermal energy required to remove water from the food material; the mechanical energy required for conveyance or airflow is less significant. Depending on the initial $\mathrm{MC}\left(\mathrm{MC}_{\mathrm{i}}\right)$ of the material and the desired final $\mathrm{MC}$ level $\left(\mathrm{MC}_{\mathrm{f}}\right)$, the removal of

\footnotetext{
* Corresponding author. Tel.: +1 479575 2841; fax: +1 4795756936.

E-mail address: tsiebenm@uark.edu (T.J. Siebenmorgen).
}

water from foodstuffs may require more energy than that required to vaporize free water (latent heat of vaporization, $h_{\mathrm{fg}}$ ) (Okos et al., 1992; Rizvi, 2005). Cenkowski et al. (1992) explained that when the MC of a material is below $12 \%$ dry basis (d.b.), the increase in intra-particle resistance to moisture migration increases the energy required to remove water. Okos et al. (1992) stated that the energy required to remove water from foods increases as the binding-force between water and the food increases. Rizvi (2005) indicated that, in general, the energy requirement for drying food materials has two main components: the energy required to evaporate free water and the energy required to remove water that is associated with the food matrix.

The entire amount of energy required to remove water from a food material has been referred to as the isosteric heat of sorption (Iglesias and Chirife, 1976), the heat of sorption (Tsami et al., 1990) and the isosteric heat of desorption (Kechaou and Maalej, 1999). Herein, this quantity will be referred to as the total heat of desorption $\left(Q_{t}\right)$. The difference between $Q_{t}$ and $h_{\mathrm{fg}}$, which has been referred to as the net isosteric heat of sorption (Iglesias and Chirife, 1976; Tsami et al., 1990), will be called the net heat of desorption $\left(Q_{n}\right)$. Aviara et al. (2004), Kechaou and Maalej (1999) and McMinn and Magee (2003) indicated that $Q_{n}$ represents the energy beyond $h_{\mathrm{fg}}$ required to remove a unit mass of water from a foodstuff due to water-solid bonds. The strength of water-solid bonds in foodstuffs varies with MC, generally increasing as MC decreases (Okos et al., 1992). Consequently, $Q_{n}$ would be expected to increase as drying progresses. Researchers have confirmed this expectation (Aviara et al., 2004; Cenkowski et al., 1992; Mulet et al., 1999; Toğrul and Arslan, 2006; Tsami et al., 1990; Zuritz and Singh, 1985). Cenkowski et al. (1992) found that the energy required to remove water from grain is close to $h_{\mathrm{fg}}$ for MCs above $20 \%$ (d.b.). However, Johnson and Dale (1954) reported that energy requirements to 
remove water from wheat and shelled corn at MCs above $14 \%$ (d.b.) are close to $h_{\mathrm{fg}}$.

Since $Q_{\mathrm{n}}$ is the theoretical minimum energy above $h_{\mathrm{fg}}$ required to remove a unit mass of water from a particular food (Rizvi, 2005), it is important to establish the relationship between $Q_{n}$ and $\mathrm{MC}$ in order to quantify the theoretical energy requirements for drying rice. In addition, it is possible that the relationship between $Q_{n}$ and MC changes depending on kernel properties, including kernel temperature (Truong et al., 2005). Therefore, it is also relevant to investigate energy requirements of different rice types, cultivars and $T$ levels. Thus, $Q_{t}$ should be determined as a function of MC and $T$ for a given rice type/cultivar. Actual energy requirements for a specific dryer can be compared to this ideal situation, and thus efficiencies for different commercial dryers can be calculated.

Little research has assessed theoretical energy requirements for drying rice, particularly for different rice types and current cultivars. Iguaz and Vírseda (2007) estimated $Q_{\mathrm{n}}$ values at different MC levels for medium-grain rough rice; Toğrul and Arslan (2006) and Zuritz and Singh (1985) estimated $Q_{t}$ values at different MC levels for long-grain and medium-grain rough rice, respectively. Researchers have used the Clausius-Clapeyron equation, in combination with sorption isotherm data, to calculate heats of desorption for diverse foodstuffs (Aviara and Ajibola, 2002; Aviara et al., 2004; Chen, 2006; Iglesias and Chirife, 1976; Iguaz and Vírseda, 2007; Kechaou and Maalej, 1999; Mulet et al., 1999; Tolaba et al., 2004; Toğrul and Arslan, 2006; Tsami et al., 1990).

The fact that sorption isotherms of foodstuffs demonstrate hysteresis is an indication of irreversibility, which has posed doubts on the reliability of the Clausius-Clapeyron equation for determining $Q_{n}$ and $Q_{t}$ (Iglesias and Chirife, 1976; McLaughlin and Magee, 1998). However, Iglesias and Chirife (1976), after analyzing works performed by other researchers who compared the Clausius-Clapeyron approach to calorimetric heats, concluded that the heats of irreversible processes are small enough to be neglected when calculating energy requirements for drying foodstuffs. Mulet et al. (1999) obtained good agreement between calorimetric heat measurements using a thermogravimetric analyzer (TGA) in combination with a differential scanning calorimeter (DSC) and those obtained from the Clausius-Clapeyron method for potato starch and cauliflower. Consequently, the application of the Clausius-Clapeyron method was deemed appropriate for estimating energy requirements for drying rice.

The objectives of this study were (1) to calculate $Q_{n}$ and $Q_{t}$ values at various MCs and Ts for different types of rice using equilibrium moisture content (EMC) data and the Clausius-Clapeyron equation, (2) to mathematically model $Q_{t}$ as a function of MC and $T$ for the rice types under study, (3) to develop an equation that predicts the theoretical energy required to dry rice from varying $\mathrm{MC}_{\mathrm{i}}$ to a desired $\mathrm{MC}_{\mathrm{f}}$.

\section{Materials and methods}

\subsection{Sorption isotherms}

EMC data were obtained from two previous studies. Elevatedtemperature desorption isotherms $\left(60,70,80\right.$ and $\left.90^{\circ} \mathrm{C}\right)$ for long-grain "Cybonnett" rough rice were obtained from Ondier et al. (2010). In addition, rough rice sorption isotherms at low temperatures $\left(10,20,30,45\right.$ and $\left.60^{\circ} \mathrm{C}\right)$ for long-grains "Wells" and "CL XL730", medium-grain "Jupiter" and a long-grain parboiled rice of unknown cultivar were obtained from Ondier et al. (2011). The data from both studies were used to calculate $Q_{t}$ and $Q_{n}$ at selected MCs and Ts.

\subsection{Heat of desorption calculation}

$Q_{t}$ was calculated using the form of the Clausius-Clapeyron equation developed by Othmer (1940):

$\ln \left(p_{\mathrm{v}}\right)=\left(\frac{Q_{\mathrm{t}}}{h_{\mathrm{fg}}}\right) \ln \left(p_{\mathrm{s}}\right)+c$

where $p_{\mathrm{v}}$ is water vapor pressure in the rice kernel associated with a particular $T, p_{\mathrm{s}}$ is vapor pressure of pure water associated with a particular $T, \mathrm{Q}_{\mathrm{t}}$ is the total heat of desorption ( $\mathrm{kJ} / \mathrm{kg}$ water), $h_{\mathrm{fg}}$ is the latent heat of vaporization of pure water at a given $T(\mathrm{~kJ} / \mathrm{kg}$ water), $c$ is an integration constant.

$Q_{\mathrm{t}} / h_{\mathrm{fg}}$ was calculated from the slope of the regression line relating $\ln \left(p_{\mathrm{v}}\right)$ to $\ln \left(p_{\mathrm{s}}\right)$ at different Ts for a specific MC; the slope of the line equals $Q_{\mathrm{t}} / h_{\mathrm{fg}}$ for a specific MC. The $p_{\mathrm{v}}$ values were calculated from ERH data using the following relationship:

$\mathrm{ERH}=\frac{p_{\mathrm{v}}}{p_{\mathrm{s}}}$

ERH is equilibrium relative humidity in a decimal form.

It is critical to select an appropriate equation to predict ERH using $T$ and MC as inputs in order to calculate $Q_{t}$. Research indicates that the modified Chung-Pfost equation (Chung and Pfost, 1967; Pfost et al., 1976) best describes rice isotherm data (Basunia and Abe, 1999; Ondier et al., 2011):

$\mathrm{ERH}=\exp \left[-\frac{A}{T+C} \exp (-B \cdot \mathrm{MC})\right]$

where $A, B$ and $C$ are constants, MC is expressed in a d.b. decimal form, $T$ is temperature $\left({ }^{\circ} \mathrm{C}\right)$ and $\mathrm{ERH}$ is equilibrium relative humidity expressed in a decimal form. The values of the constants $A, B$ and $C$ were obtained from Ondier et al. (2010, 2011), depending on the temperature range and cultivar. Zuritz and Singh (1985) reported that among the isotherm equations at that time, only the ChungPfost equation was appropriate for heat of desorption calculations, because it was the only equation in compliance with the necessary mathematical restriction that the heat of desorption decreases with an increase in temperature. Thus, $p_{\mathrm{v}}$ values were calculated using Eqs. (2) and (3) and $p_{\mathrm{s}}$ values from the psychometric relationships in ASAE (1998).

Linear regressions of $\ln \left(p_{\mathrm{v}}\right)$ vs. $\ln \left(p_{\mathrm{s}}\right)$ were developed for selected MCs. $Q_{t} / h_{\text {fg }}$ was estimated from the slope of each curve for a given MC. The ratio $Q_{\mathrm{t}} / h_{\mathrm{fg}}$ was assumed to be constant in the temperature range over which the data were collected. Thus, $Q_{t}$ for a given $\mathrm{MC}$ and $T$ combination was calculated using a consistent $Q_{\mathrm{t}} / h_{\mathrm{fg}}$ ratio for a given MC level: however, to account for varying $T$ levels, $h_{\mathrm{fg}}$ was varied to correspond to the desired $T$ level using Perry and Chilton (1973). The net heat of desorption $Q_{n}$ was then calculated using Eq. (4).

$Q_{\mathrm{t}}=Q_{\mathrm{n}}+h_{\mathrm{fg}}$

\subsection{Heat of desorption prediction}

In order to mathematically express $Q_{t}$ as a function of MC and $T$ for the different types of rice, $Q_{t}, M C$ and $T$ data were used to statistically determine the constants of the relationship used by Truong et al. (2005):

$Q_{\mathrm{t}}=A_{1}+B_{1} \cdot T+\left(A_{2}+B_{2} \cdot T\right) \exp \left(-A_{3} \cdot \mathrm{MC}\right)$

where $A_{1}, A_{2}, A_{3}, B_{1}$ and $B_{2}$ are constants of the equation estimated iteratively by fitting the non-linear model. $Q_{t}$ is in $\mathrm{J} / \mathrm{kg}$ water, MC is in dry basis, decimal and $T$ is in $\mathrm{K}$.

Truong et al. (2005) successfully used this model to describe $Q_{t}$ data for a mixture of maltodextrin-sucrose. Non-linear least squares regression analyses were performed on the data to obtain 
Table 1

Equilibrium relative humidities (\%) of long-grain "Cybonnett" rough rice at the indicated moisture contents and temperatures calculated using the modified Chung Pfost equation (Ondier et al., 2010).

\begin{tabular}{lllllllll}
\hline Temperature, ${ }^{\circ} \mathrm{C}$ & \multicolumn{7}{l}{ Moisture content, \% w.b. } \\
\cline { 2 - 9 } & 8 & 10 & 12 & 14 & 16 & 18 & 20 & 22 \\
\hline 60 & 26 & 49 & 70 & 84 & 92 & 96 & 98 & 99 \\
70 & 37 & 60 & 77 & 88 & 94 & 97 & 99 & 99 \\
80 & 46 & 67 & 82 & 91 & 95 & 98 & 99 & 99 \\
90 & 53 & 72 & 84 & 92 & 96 & 98 & 99 & 99 \\
\hline
\end{tabular}

the constants for Eq. (5). Root mean square error (RMSE) and standard error of the coefficients (SE) were used to assess the fit and precision of the estimates.

\subsection{Energy requirements per unit mass of rice and per unit mass of water removed}

$Q_{t}$ data was used to develop an equation that predicts the theoretical energy required per unit mass dry matter of rice $\left(Q_{\text {Trice }}\right)$ to dry rice from a given $\mathrm{MC}_{\mathrm{i}}$ to a $\mathrm{MC}_{\mathrm{f}}$ when drying at a given $T$, similar in approach to Tsami et al. (1990). To calculate $Q_{\text {Trice, }}$ an integration of Eq. (5) was performed:

$Q_{\text {Trice }}=\int_{\mathrm{MC}_{\mathrm{i}}}^{\mathrm{MC}_{\mathrm{f}}} Q_{\mathrm{t}} \mathrm{dMC}$

where $Q_{\text {Trice }}$ is the energy required to dry rice from $M C_{i}$ to $M C_{f}$ per unit dry mass of rice at a given $T$. Thus, $T$ was considered constant throughout the integration.

Substituting Eq. (5) into Eq. (6) and integrating:

$$
\begin{aligned}
Q_{\text {Trice }}= & \int_{\mathrm{MC}_{\mathrm{i}}}^{\mathrm{MC}_{\mathrm{f}}}\left(A_{1}+B_{1} \cdot T+\left(A_{2}+B_{2} \cdot T\right) \exp \left(-A_{3} \cdot \mathrm{MC}\right)\right) \mathrm{dMC} \\
= & A_{1}\left[\mathrm{MC}_{\mathrm{f}}-\mathrm{MC}_{\mathrm{i}}\right]+B_{1} \cdot T \cdot\left[\mathrm{MC}_{\mathrm{f}}-\mathrm{MC}_{\mathrm{i}}\right]+\frac{\left(A_{2}+B_{2} \cdot T\right)}{-A_{3}} \\
& \times\left(\exp \left(-A_{3} \cdot \mathrm{MC}_{\mathrm{f}}\right)-\exp \left(-A_{3} \cdot \mathrm{MC}_{\mathrm{i}}\right)\right)
\end{aligned}
$$

Table 2

Net heat of desorption $\left(Q_{n}\right)$, total heats of desorption $\left(Q_{t}\right)$ and standard errors (SE) of $Q_{n}$ and $Q_{t}$, calculated from linear regressions using the Clausius-Clapeyron equation at the selected moisture content levels for long-grain "Cybonnett" rough rice at $60{ }^{\circ} \mathrm{C}$. The value of $h_{\mathrm{fg}}$ was $2359 \mathrm{~kJ} / \mathrm{kg}$ water.

\begin{tabular}{cclc}
\hline Moisture content, \% w.b. & $Q_{\mathrm{n}}, \mathrm{kJ} / \mathrm{kg}$ water & $Q_{\mathrm{t}}, \mathrm{kJ} / \mathrm{kg}$ water & $\mathrm{SE}, \mathrm{kJ} / \mathrm{kg}$ water \\
\hline 8 & 1381 & 3741 & 166 \\
10 & 743 & 3102 & 106 \\
12 & 359 & 2718 & 57 \\
14 & 180 & 2539 & 29 \\
16 & 81 & 2440 & 9 \\
18 & 42 & 2401 & 9 \\
20 & 18 & 2377 & 10 \\
22 & 0 & 2359 & 0
\end{tabular}

Table 3

Estimated constants of Eq. (5) and associated root mean square errors (RMSEs) for long-grains "Wells", “CL XL730" and "Cybonnett", medium-grain "Jupiter”, parboiled rice and for a general model describing all non-parboiled, long-grain rice cultivars.

\begin{tabular}{lllllll}
\hline \multirow{2}{*}{ Cultivar } & Parameter & & & & \multirow{2}{*}{ RMSE } \\
\cline { 2 - 5 } & $A_{1}$ & $A_{2}$ & $A_{3}$ & $B_{1}$ & $B_{2}$ & \\
\hline "Jupiter" & $3,150,878$ & $12,725,771$ & 23.2 & -2377 & -9601 & 0.22 \\
"Wells" & $3,150,927$ & $11,509,211$ & 23.4 & -2377 & -8683 & 0.23 \\
"Cybonnett" & $3,200,035$ & $19,950,786$ & 27.1 & -2521 & $-15,719$ & 1.15 \\
"CL XL730" & $3,150,916$ & $10,117,409$ & 22.7 & -2377 & -7632 & 0.23 \\
General & $3,189,745$ & $9,742,417$ & 24.2 & -2496 & - & 4.0 \\
Parboiled & $3,151,394$ & $8,107,920$ & 23.0 & -2377 & -6117 & 0.72 \\
\hline
\end{tabular}

By using Eq. (7), expressions for each type of rice were obtained, whereby energy requirements for drying a unit mass of rice dry matter were obtained for given $\mathrm{MC}_{\mathrm{i}}, \mathrm{MC}_{\mathrm{f}}$ and $T$ inputs. The value of $Q_{\text {Trice }}(\mathrm{J} / \mathrm{kg}$ dry matter rice) is negative but the absolute value was reported.

To express the energy requirements to dry rice from an $\mathrm{MC}_{\mathrm{i}}$ to an $\mathrm{MC}_{\mathrm{f}}$ on a per unit mass of water removed basis, $Q_{\text {Trice }}$ from Eq. (7) was divided by $\Delta m_{\text {evap }}$ the mass of water removed in the drying process per unit rice dry matter, which can be expressed as:

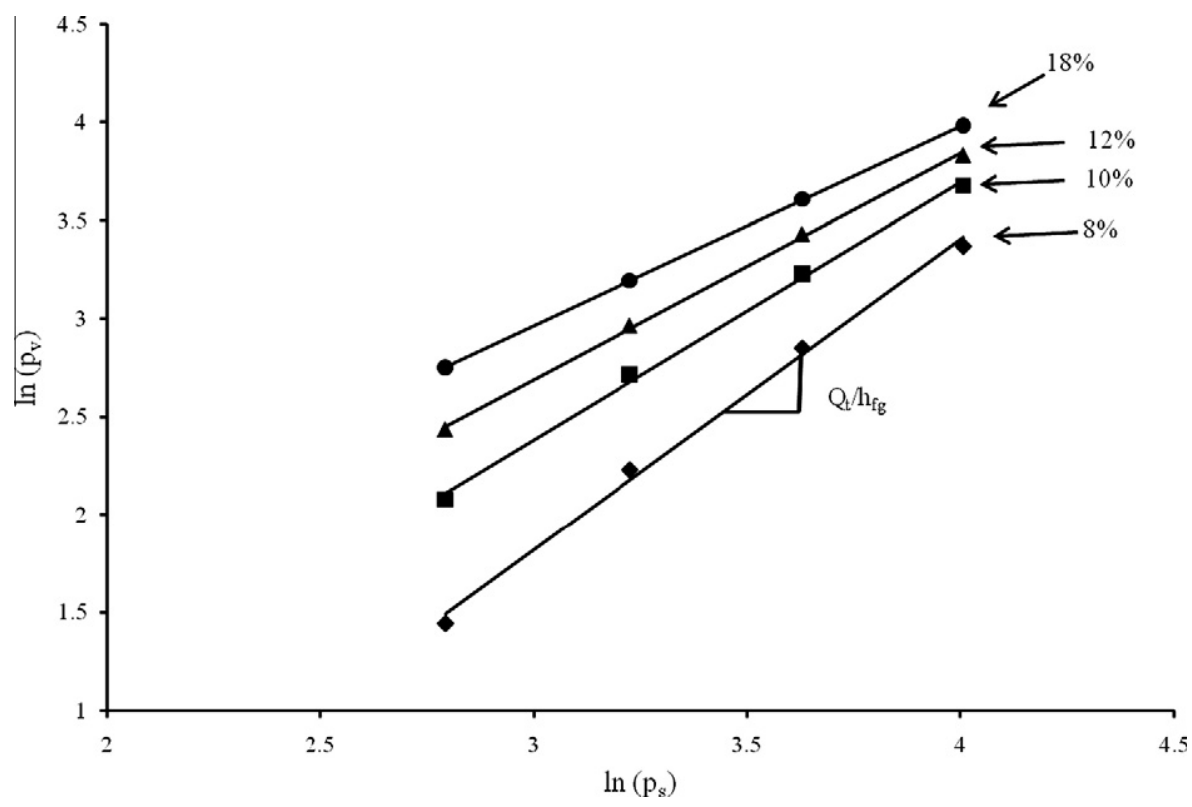

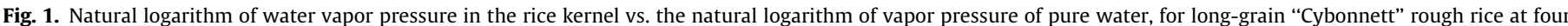

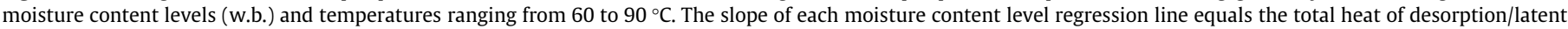
heat of evaporation of pure water $\left(Q_{\mathrm{t}} / h_{\mathrm{fg}}\right)$ quotient, per Eq. (1). 


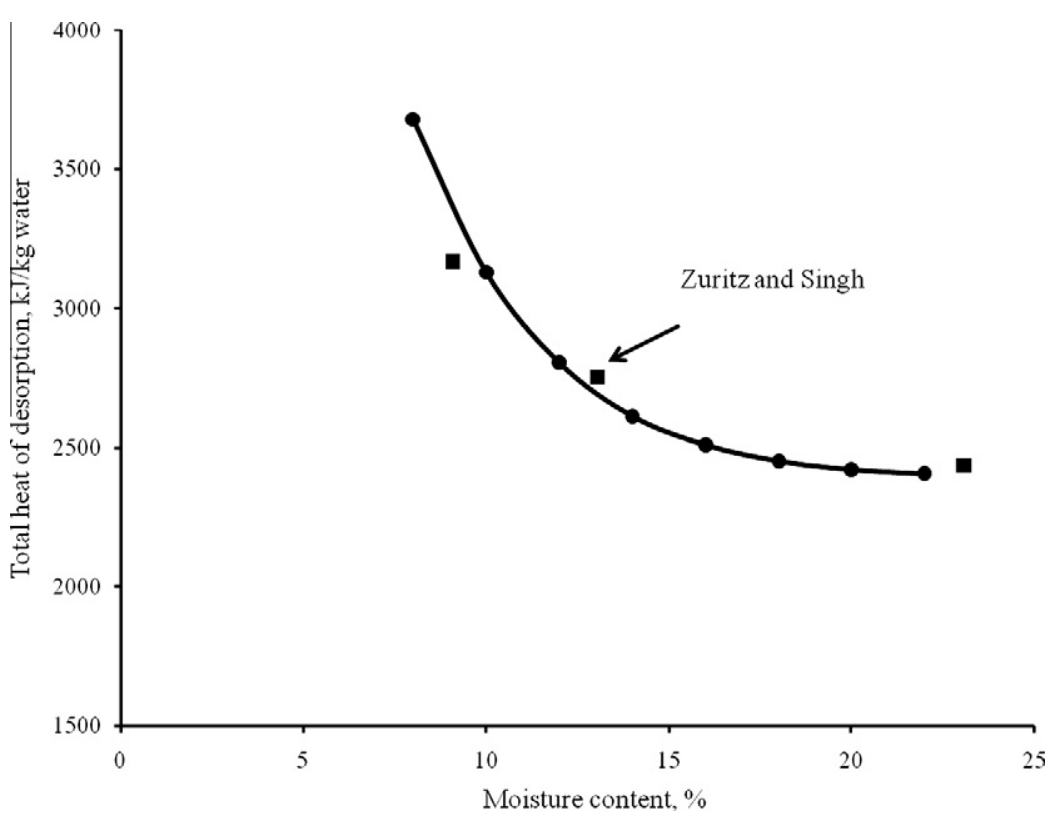

Fig. 2. Total heat of desorption $\left(Q_{t}\right)$ as a function of moisture content (\% wet basis) for medium-grain "Jupiter”, at $45{ }^{\circ} \mathrm{C}$ and those reported for a medium-grain rice at $40{ }^{\circ} \mathrm{C}$ by Zuritz and Singh (1985).

Table 4

Predicted values and confidence intervals for the total heat of desorption $\left(Q_{t}\right)$ as obtained from Eq. (5) at $12.5 \%$ moisture content and $60{ }^{\circ} \mathrm{C}$ and for the rice types indicated.

\begin{tabular}{lll}
\hline Rice type & $\begin{array}{l}Q_{\mathrm{t}}, \mathrm{kJ} / \mathrm{kg} \\
\text { water }\end{array}$ & $\begin{array}{l}\text { 95\% Confidence interval, kJ/kg } \\
\text { water }\end{array}$ \\
\hline Medium-grain "Jupiter" & 2705 & $2704-2707$ \\
Long-grain “Wells" & 2665 & $2664-2666$ \\
Long-grain “Cybonnett" & 2665 & $2659-2672$ \\
Long-grain “CL XL730" & 2656 & $2655-2657$ \\
Long-grain non-parboiled & 2669 & $2656-2671$ \\
$\quad$ general) & & \\
Long-grain parboiled & 2590 & $2587-2593$ \\
\hline
\end{tabular}

$\Delta m_{\text {evap }}=\mathrm{MC}_{\mathrm{i}}-\mathrm{MC}_{\mathrm{f}}$

It is emphasized that $Q_{\text {Trice }}$ can thus be expressed as drying energy required per unit mass of rice dry matter, Eq. (7), or energy per unit mass of water removed by dividing Eq. (7) by $\Delta m_{\text {evap }}$ (Eq. (8)).

All statistical analyses were performed using JMP 8.0.1 software (SAS Institute, Inc.).

\section{Results and discussion}

Table 1 shows the predicted ERH values, at temperatures ranging from 60 to $90^{\circ} \mathrm{C}$, calculated from Eq. (3), for selected MCs for long-grain "Cybonnett" rough rice (Ondier et al., 2010). For each MC value, linear regressions of $\ln \left(p_{\mathrm{v}}\right)$ vs. $\ln \left(p_{\mathrm{s}}\right)$ were performed using Eq. (1); Fig. 1 shows the corresponding linear regressions obtained for the MC levels of $8 \%, 10 \%, 12 \%$ and $18 \%$. $Q_{t}$ was calculated from the slope of each line. The same procedure was used for estimating $Q_{t}$ when using EMC data collected at Ts ranging from 10 to $60{ }^{\circ} \mathrm{C}$ for the four lots listed previously (data not shown). $Q_{n}$ was calculated through Eq. (4). The slope of the $\ln \left(p_{\mathrm{v}}\right)$ vs. $\ln \left(p_{\mathrm{s}}\right)$ line approaches unity as MC increases (Fig. 1). Consequently, $Q_{t}$ approaches $h_{\mathrm{fg}}$ as MC increases. This can also be interpreted to indicate that the energy required to dry rice, in terms of energy per unit moisture removed, increases as drying progresses. The same trends were observed for all rice types. Values of $Q_{n}$ for long-grain "Cybonnett" at $60{ }^{\circ} \mathrm{C}$ are tallied in Table 2. The standard error of $Q_{\mathrm{n}}$ is equal to the SE of $Q_{\mathrm{t}}$ because the difference between these two values is a constant $\left(h_{\mathrm{fg}}\right)$. Iguaz and Vírseda (2007) reported for medium-grain rough rice, $Q_{n}$ values from 139 to $1021 \mathrm{~kJ} / \mathrm{kg}$ water for MCs ranging from $19 \%$ to $0.04 \%$ and Ts from 40 to $80^{\circ} \mathrm{C}$. The $Q_{n}$ values obtained in this study are greater than those of Iguaz and Vírseda (2007) at low MCs and are lower than those of Iguaz and Vírseda (2007) at high MCs.

\subsection{Total heat of desorption prediction}

Heats of desorption obtained from Eq. (1), along with corresponding MCs and Ts, were used to determine the parameters of Eq. (5) for each type of rice. Because of great differences among the SEs of $Q_{t}$ across MCs (Table 2), non-linear regressions were performed using the weighting feature of JMP (SAS Institute, Inc.), in which the SEs were weighted by using the reciprocal of SE (1/ SE). RMSE and equation constants obtained for Eq. (5) are shown in Table 3. Eq. (5) describes the experimental data well based on the low RMSE values for every rice type (Table 3). Additionally, the model consistently converged with little iteration to the estimates of the parameters, which is an indication of goodness of fit. When Iguaz and Vírseda (2007) modeled heat of desorption data, using the modified Guggenheim Anderson De Boer (GAB) isotherm equation (Anderson, 1946; De Boer, 1953; Guggenheim, 1966; Jayas and Mazza, 1993) to predict ERH, they found that the Kechaou and Maalej model (Kechaou and Maalej, 1999) was appropriate in describing $Q_{n}$ vs. MC data. Heat of desorption data for rice reported by Zuritz and Singh (1985), who used the Chung-Pfost equation to predict ERH, showed an exponential trend (Fig. 2), which is in agreement with the results obtained in this study. However, it is noted that Zuritz and Singh (1985) did not test any model to describe heat of desorption vs. MC. Discrepancies in findings can be explained by Souza et al. (2006), in that regardless of the crop, $Q_{n}$, and thus $Q_{t}$, behavior varies, depending on the equation that is used to predict ERH from sorption isotherm data. Rice was among the crops studied by Souza et al. (2006) who observed that when the modified Chung-Pfost equation was used to predict $\mathrm{ERH}$, the heat of desorption curve followed an 


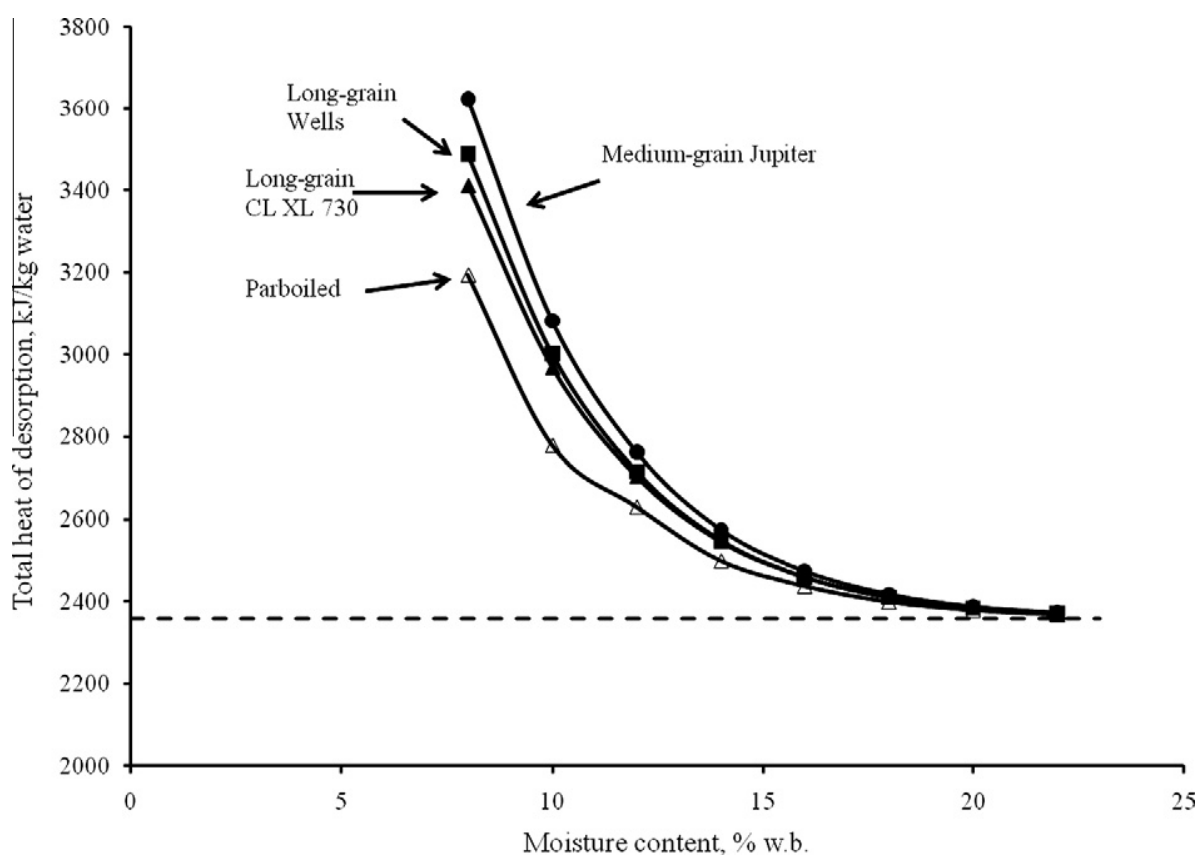

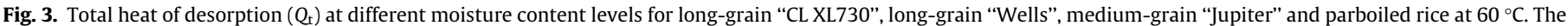
value of $h_{\mathrm{fg}}$ is indicated and was $2359 \mathrm{~kJ} / \mathrm{kg}$ water.

Table 5

Equations based on Eq. (7) and Table 3 to predict the energy required to dry rice from an $\mathrm{MC}_{\mathrm{i}}$ to a desired $\mathrm{MC}_{\mathrm{f}}\left(Q_{\text {Trice }}\right)$ in $\mathrm{J} / \mathrm{kg}$ dry matter, for the indicated rice types. ${ }^{\text {a }}$

\begin{tabular}{|c|c|c|}
\hline Rice type & Equation & Temp. range, ${ }^{\circ}{ }^{\circ} \mathrm{C}$ \\
\hline Medium-grain/non-parboiled & $Q_{\text {Trice }}=(3,150,878-2377 T)\left(\mathrm{MC}_{\mathrm{f}}-\mathrm{MC}_{\mathrm{i}}\right)+\left[e^{-23.2 \mathrm{MC}_{\mathrm{f}}}-e^{-23.2 \mathrm{MC}_{\mathrm{i}}}\right] \frac{(12,725,771-9601 T)}{-232}$ & $10-60$ \\
\hline Long-grain/non-parboiled & $Q_{\text {Trice }}=(3,189,745-2496 T)\left(\mathrm{MC}_{\mathrm{f}}-\mathrm{MC}_{\mathrm{i}}\right)+\left[e^{-24.2 \mathrm{MC}_{\mathrm{f}}}-e^{\left.-24.2 \mathrm{MC}_{\mathrm{i}}\right] \frac{(9,742,417)}{-24.2}}\right.$ & $10-90$ \\
\hline Long-grain/parboiled & $Q_{\text {Trice }}=(3,151,394-2377 T)\left(\mathrm{MC}_{\mathrm{f}}-\mathrm{MC}_{\mathrm{i}}\right)+\left[e^{-23.0 \mathrm{MC}_{\mathrm{f}}}-e^{-23.0 \mathrm{MC}_{\mathrm{i}}}\right] \frac{(8,107,920-6117 T)}{-23.0}$ & $10-60$ \\
\hline
\end{tabular}

${ }^{\mathrm{a}} \mathrm{MC}_{\mathrm{i}}$ and $\mathrm{MC}_{\mathrm{f}}$ are inputs on a dry basis.

b Temperature range over which EMC data were collected.

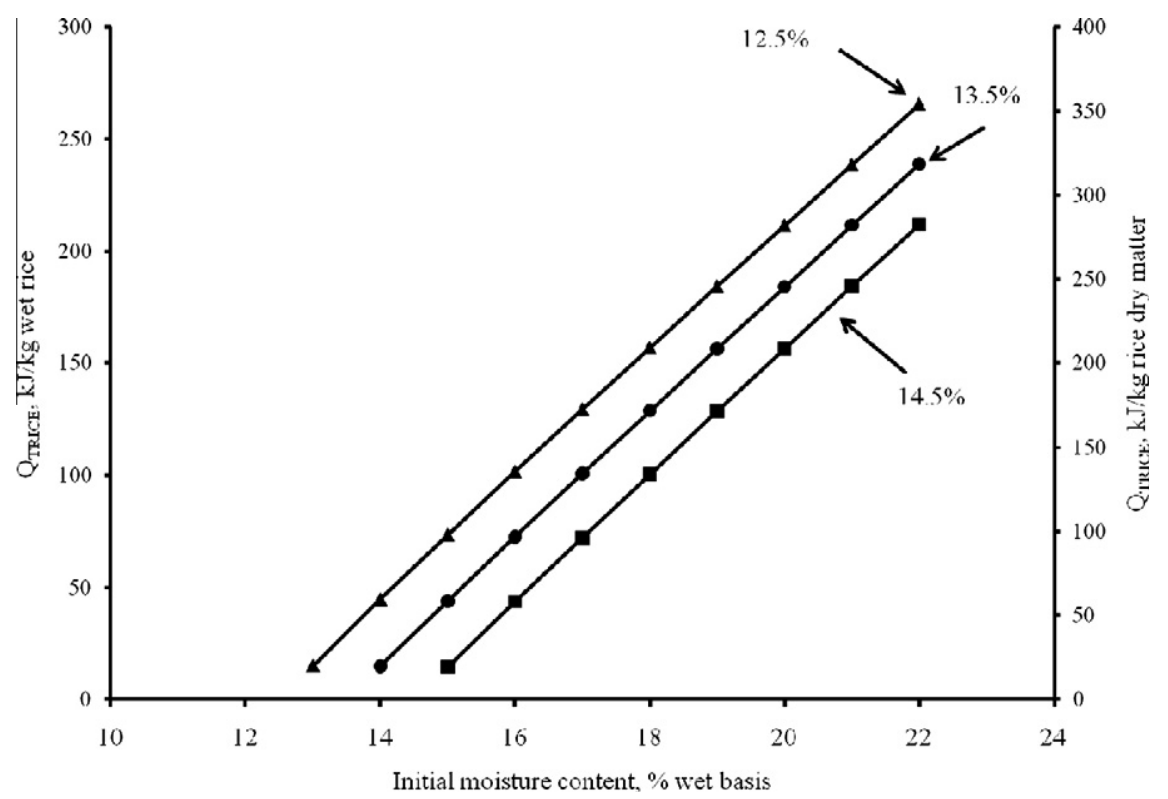

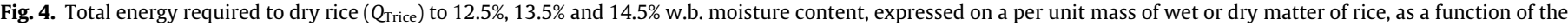
initial moisture content of the rice for long-grain, non-parboiled rice at $60{ }^{\circ} \mathrm{C}$.

exponential trend. In the case of other ERH equations, such as the modified Henderson equation (Thompson et al., 1968), the $Q_{n}$ curve was linear.
To assess differences in drying energy requirements among rice cultivars, a final, target MC of $12.5 \%$ was chosen based on the fact that $12.5 \%$ is a typical, desired final MC in the rice industry. Since $Q_{t}$ 


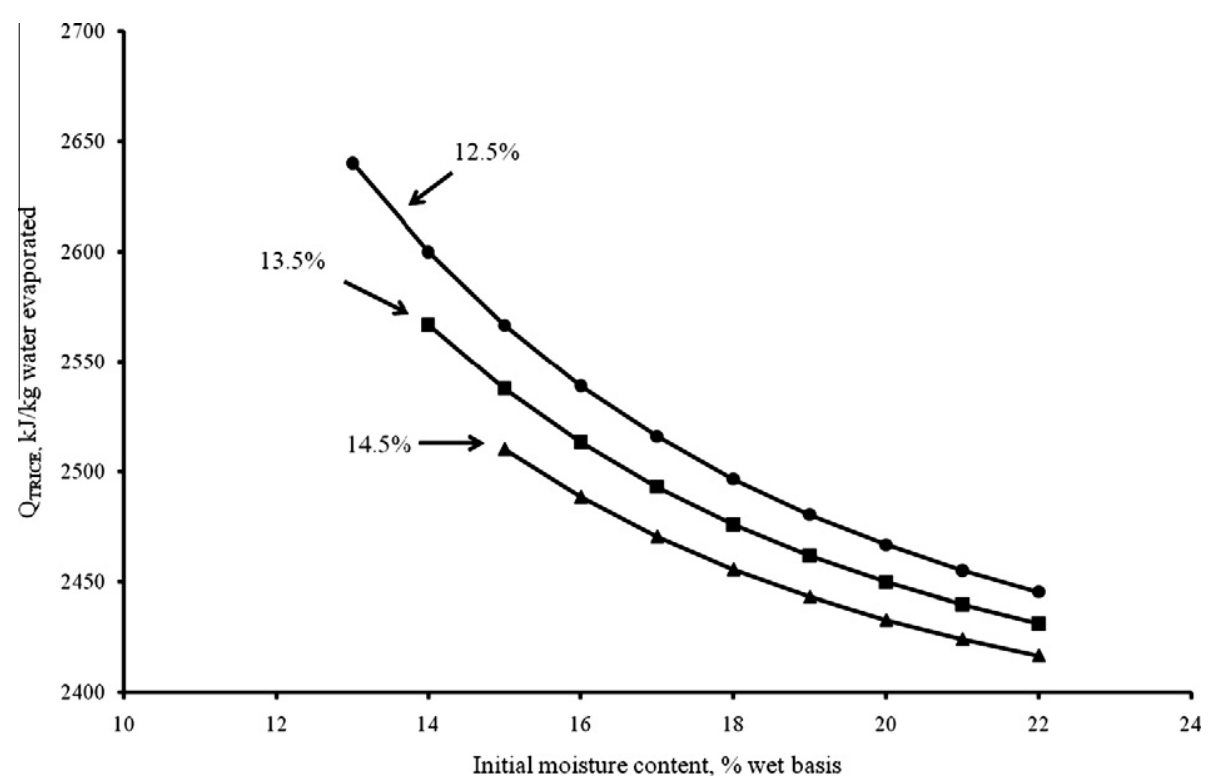

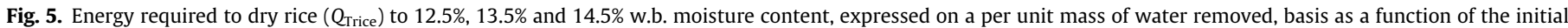
moisture content of rice for long-grain non-parboiled rice at $60{ }^{\circ} \mathrm{C}$.

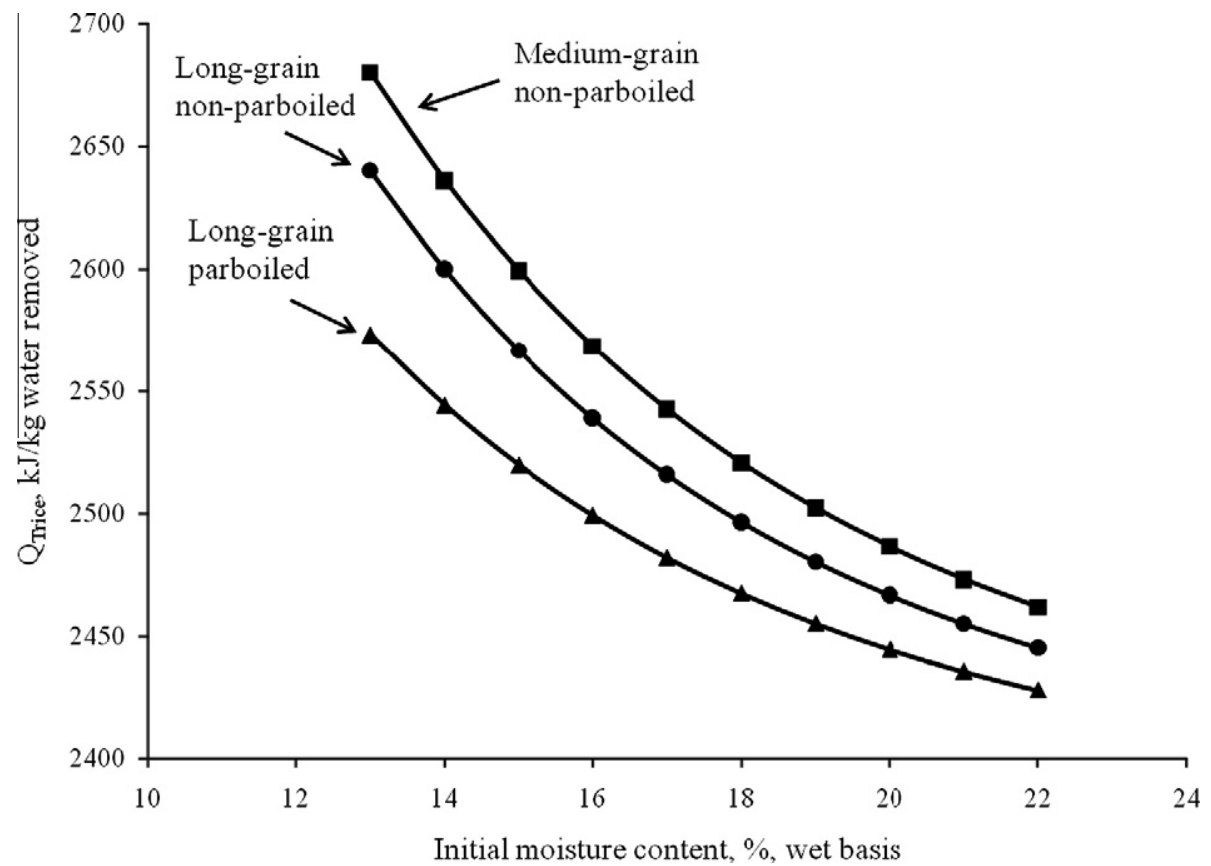

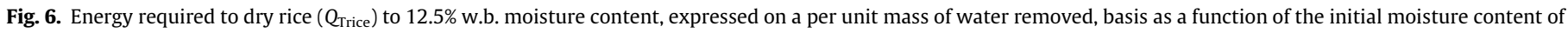
the rice for long-grain non-parboiled, long-grain parboiled and medium-grain non-parboiled rice at $60{ }^{\circ} \mathrm{C}$.

increases as MC decreases, $Q_{t}$ is greatest at the end of drying and consequently it was relevant to evaluate if the differences in energy requirements among rice types were significant at this MC level. In addition, a $T$ of $60^{\circ} \mathrm{C}$ was selected to compare energy requirements among rice cultivars.

Table 4 shows $Q_{t}$ values predicted using Eq. (5), and the $95 \%$ confidence intervals (CIs) obtained for each predicted $Q_{t}$ value for the different rice types. The $Q_{t}$ predicted for medium-grain "Jupiter" was significantly greater than the other rice types since the CI of "Jupiter" does not overlap with the other CIs; thus, the energy required to remove a unit mass of water from medium-grain rough rice with $12.5 \% \mathrm{MC}$ at $60{ }^{\circ} \mathrm{C}$ is estimated to be significantly greater than that required for the other rice types (Table 4). Long-grain parboiled rice required significantly less energy to remove a unit mass of water from rough rice with $12.5 \% \mathrm{MC}$ at $60{ }^{\circ} \mathrm{C}$ than that required for non-parboiled rice. The $Q_{t}$ CIs of long-grains "Wells" and "Cybonnett" do overlap. This indicated that the difference in $Q_{t}$ between these two cultivars at $12.5 \% \mathrm{MC}$ and $60{ }^{\circ} \mathrm{C}$ was not necessarily significant. While $Q_{t}$ values for long-grain "CLXL 730" were significantly lower than those of long-grains Wells and "Cybonnet", the general level was similar among long-grains.

As the differences in $Q_{t}$ between "Wells" and "Cybonnett" were not significant and as $Q_{t}$ of "CL XL730" was similar to those of "Wells" and "Cybonnett", one general model for long-grain, 


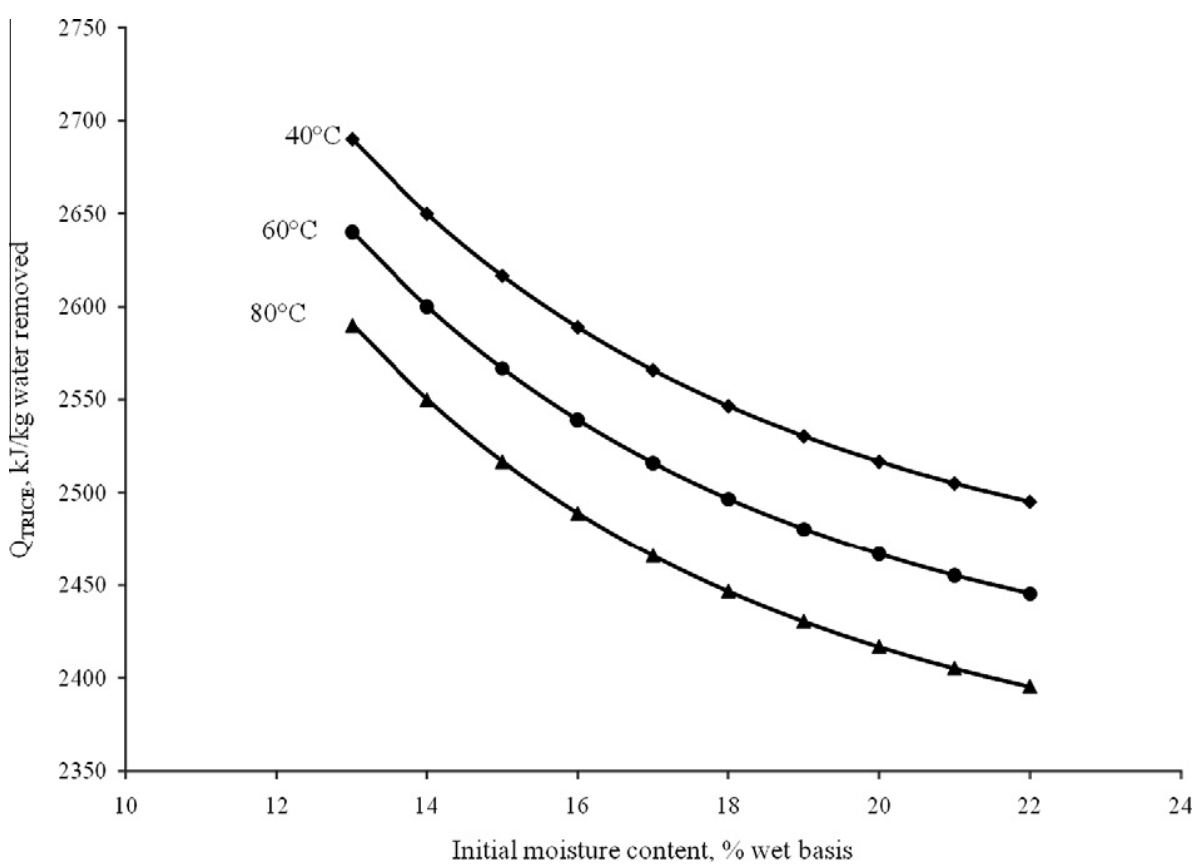

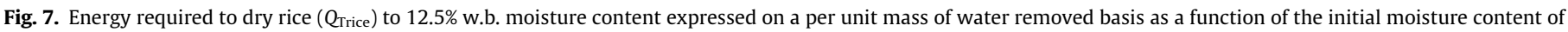
the rice for long-grain non-parboiled rice.

non-parboiled rice was developed. The predicted range of $Q_{t}$ for general, long-grain cultivars at $12.5 \% \mathrm{MC}$ and $60{ }^{\circ} \mathrm{C}$ is shown in Table 4, while the RMSE for this general model is shown in Table 3.

It is noted that the term $B_{2}$ was not significant when fitting the general model. A possible explanation for this could be that the effect of cultivar on $Q_{t}$ was greater than that of $T$ in affecting the exponential term of Eq. (5). Therefore, when considering all the cultivars separately, the $B_{2}$ coefficient was significant but when all long-grain cultivars were used to develop the general model, the $B_{2}$ coefficient was not significant.

\subsection{Total heat of desorption results}

The values of $Q_{t}$ and their corresponding SE for long-grain "Cybonnett" are shown in Table 2. The total heat of desorption increases exponentially as MC decreases for all rice types (Fig. 3). There was a sharp increase in $Q_{t}$ for MCs below $15 \%$ and $Q_{t}$ approached $h_{\mathrm{fg}}$ at MCs around 20\%. The increase in $Q_{\mathrm{t}}$ as MC decreases indicates that water is increasingly bound to the rice matrix as MC decreases. This is of interest to the rice industry as rice is dried within the range in which $Q_{t}$ increases considerably. $Q_{t}$ varied for long-grain "Wells" from 2371 to 3488, for long-grain "CL XL730" from 2371 to 3413 , for medium-grain "Jupiter" from 2372 to 3624 and for parboiled rice from 2368 to $3194 \mathrm{~kJ} / \mathrm{kg}$ water, for MCs from $8 \%$ to $22 \%$ at $60{ }^{\circ} \mathrm{C}$. Zuritz and Singh (1985) reported $Q_{t}$ values for medium-grain rough rice from 2438 to $4015 \mathrm{~kJ} / \mathrm{kg}$ water, for MCs from $4.8 \%$ to $23 \%$, at $40{ }^{\circ} \mathrm{C}$.

Based on the trends shown in Fig. 3, parboiled rice requires less energy to be dried than non-parboiled rice lots at MCs below $15 \%$. A possible explanation for this would be that during the parboiling process, part of the hull typically cracks, reducing the resistance to moisture transfer. Another possibility is that since starch gelatinizes during the parboiling process, the change in starch structure could increase the diffusivity of the endosperm, producing less resistance to moisture flow.

Fig. 3 also shows the general effect of kernel dimensions and shape on the energy requirements to dry rice. Boyce (1965) referred to an unspecified study stating that kernels with similar dimensions would have similar energy requirements. Fig. 3 shows that the energy requirements for long-grain, pureline "Wells" and for long-grain, hybrid CLXL730 are equivalent, reinforcing the Boyce (1965) statement. Nevertheless, more cultivars should be studied to confirm this hypothesis.

Another observation regarding kernel dimensions is shown in Fig. 3 in that the energy requirements for drying the medium-grain cultivar are slightly greater than that of the long-grains for MCs below $15 \%$. Since medium-grain kernels are thicker, wider and shorter than long-grains, moisture has to migrate through a longer pathway, producing an internal resistance that is greater in medium-grain than long-grain rice. Therefore, the energy required to remove water from medium-grain rice would be expected to be greater than that of long-grain rice. Cnossen et al. (2002) found that the effect of drying air conditions on the drying rate of a medium-grain cultivar was less significant than for a long-grain, presumably due to the fact that internal resistance to moisture transport is greater in the first case. The $Q_{t}$-results obtained for medium-grain "Jupiter" at $45^{\circ} \mathrm{C}$ in this study and those for a medium-grain rice at $40^{\circ} \mathrm{C}$ reported by Zuritz and Singh (1985) are shown in Fig. 2. The results are in general agreement, although a slight difference exists at the lowest MC level reported by Zuritz and Singh (1985).

\subsection{Energy requirements to dry rice from an $M C_{i}$ to an $M C_{f}$}

Based on Eq. (7), mathematical expressions that predict the energy required to dry rice from an $\mathrm{MC}_{\mathrm{i}}$ to a desired $\mathrm{MC}_{\mathrm{f}}\left(Q_{\text {Trice }}\right)$ at a given drying $T$ were developed. These equations were developed using the appropriate $A_{1}, A_{2}, A_{3}, B_{1}$ and $B_{2}$ values from Table 3 . The resulting equations are shown in Table 5. Eq. (7) can be adjusted to predict energy requirements to dry rice from an $\mathrm{MC}_{\mathrm{i}}$ to an $\mathrm{MC}_{\mathrm{f}}$ on a per unit mass of water removed basis by dividing by the mass of water removed (Eq. (8)).

Fig. 4 shows the variation of $Q_{\text {Trice }}$ (drying energy required per unit mass wet rice and per unit dry matter) with $\mathrm{MC}_{\mathrm{i}}$ for longgrain, non-parboiled rice for three $\mathrm{MC}_{\mathrm{f}}$ levels at $60^{\circ} \mathrm{C}$. $Q_{\text {Trice }}$ per unit mass wet rice was obtained by dividing $Q_{\text {Trice }}$ (Eq. (7)) by the amount of wet rice corresponding to a unit mass dry matter at the $\mathrm{MC}_{\mathrm{i}}$. The trends indicated in Fig. 4 are practically linear. 
An explanation for this would be that the linear terms of the equations shown in Table 5, representing the energy required to vaporize free water, are considerably greater than the exponential terms and therefore, the linear terms contribute considerably more to $Q_{\text {Trice. }}$ Nevertheless, in order to obtain accurate theoretical energy requirements, including both terms in the equation is necessary because as MC decreases, the contribution of Table 5 exponential term becomes more important. For instance, the exponential term is $4.2 \%$ of the $Q_{\text {Trice }}$ value when drying from $22 \%$ to $12.5 \% \mathrm{MC}$ at $60{ }^{\circ} \mathrm{C}$ but is $10.0 \%$ of $Q_{\text {Trice }}$ when drying from $14 \%$ to $12.5 \%$ at $60{ }^{\circ} \mathrm{C}$ for long-grain, non-parboiled rice.

A conventional way of quantifying drying energy requirements in the grains industry is to express energy requirements on a per unit mass of water removed. Fig. 5 shows the energy required to dry rice from an $\mathrm{MC}_{\mathrm{i}}$ to a desired $\mathrm{MC}_{\mathrm{f}}$ of $12.5 \%, 13.5 \%$ and $14.5 \%$ on a per unit mass of water removed at $60^{\circ} \mathrm{C}$. $Q_{\text {Trice }}$ decreased exponentially as $\mathrm{MC}_{\mathrm{i}}$ increases, when expressed on a per unit mass of water removed. In addition, $Q_{\text {Trice }}$ increases as $\mathrm{MC}_{\mathrm{f}}$ decreases. Both of these observations reflect the increasing importance of $Q_{n}$ at the lower MC levels. Therefore, the energy required to remove a unit mass of water from rice should not be considered constant across $\mathrm{MC}_{\mathrm{i}}$.

Fig. 6 shows that $Q_{\text {Trice }}$ decreases exponentially as $M C_{i}$ increases for the different rice types, when expressed on a per unit mass of water removed. Further, Fig. 6 confirms the findings discussed in Table 4 in that medium-grain rice required more energy than longgrains and that non-parboiled rice requires more energy than parboiled rice, when expressed on a per unit mass of water removed.

The effect of temperature on energy requirements to dry rice from $\mathrm{MC}_{\mathrm{i}}$ to $12.5 \%$ is shown in Fig. 7 . The energy required to dry rice from $\mathrm{MC}_{\mathrm{i}}$ to $12.5 \%$ decreases as drying $T$ increases. For instance, the energy required to dry rice from $20 \%$ to $12.5 \%$ at $40{ }^{\circ} \mathrm{C}$ was of $2517 \mathrm{~kJ} / \mathrm{kg}$ water removed, at $60^{\circ} \mathrm{C}$ was of $2467 \mathrm{~kJ} / \mathrm{kg}$ water removed and at $80^{\circ} \mathrm{C}$ was of $2417 \mathrm{~kJ} / \mathrm{kg}$ water removed (Fig. 7).

\section{Conclusions}

The net heat of desorption $\left(Q_{n}\right)$ and total heat of desorption $\left(Q_{t}\right)$ decreased exponentially as MC increased for all types of rice in the range of $10-90{ }^{\circ} \mathrm{C}$ and $8-22 \%$ MC. Mathematical models were developed to predict the $Q_{t}$ (the amount of energy required to remove a unit mass of water from rice with a specific MC) for rough rice of long-grains "Wells", "Cybonnett" and "CLXL730", mediumgrain "Jupiter" and long-grain, parboiled rice. The $Q_{t}$ of parboiled rice at $12.5 \% \mathrm{MC}$ and $60^{\circ} \mathrm{C}$ was significantly less than that of non-parboiled lots, and the net heat of desorption of medium-grain rough rice was significantly greater than that of long-grains at $12.5 \% \mathrm{MC}$ and $60^{\circ} \mathrm{C}$. Equations that predict the energy required to dry a unit mass of rice from an $\mathrm{MC}_{\mathrm{i}}$ to a desired $\mathrm{MC}_{\mathrm{f}}$ at a given $T$ were obtained for long-grain non-parboiled, medium-grain non-parboiled, and parboiled rice. The energy required to remove a unit mass of water when drying from a given $\mathrm{MC}_{\mathrm{i}}$ to a desired $\mathrm{MC}_{\mathrm{f}}$ decreased exponentially as $\mathrm{MC}_{\mathrm{i}}$ increased at a given $T$. These equations provide a more accurate estimate of the energy required to dry rice than the approach of simply using the latent heat of vaporization when assessing energy efficiency of a drying process.

\section{References}

Anderson, R.B., 1946. Modifications of the B.E.T. equation. Journal of American Chemical Society 68, 686-691.

Aviara, N.A., Ajibola, O.O., 2002. Thermodynamics of moisture sorption in melon seed and cassava. Journal of Food Engineering 55, 107-113.

Aviara, N.A., Ajibola, O.O., Oni, S.A., 2004. Sorption equilibrium and thermodynamic characteristics of soya bean. Biosystems Engineering 87 (2), 179-190.

ASAE, 1998. Standard D271.2 DEC94. Psychrometric Data, St. Joseph.
Basunia, M.A., Abe, T., 1999. Moisture adsorption isotherms of rough rice. Journal of Food Engineering 42 (4), 235-242, MI, USA.

Boyce, D.S., 1965. Grain moisture and temperature changes with position and time during through drying. Journal of Agricultural Engineering Research 10 (4) 333-341.

Cenkowski, S., Jayas, D.S., Hao, D., 1992. Latent heat of vaporization for selected foods and crops. Canadian Agricultural Engineering 34, 281-286.

Chen, C., 2006. Obtaining the isosteric sorption heat directly by sorption isotherm equations. Journal of Food Engineering 74 (2), 178-185.

Chung, D.S., Pfost, H.B., 1967. Adsorption and desorption of water vapor by cereal grains and their products: Part 2. Development of the general isotherm equation. Transactions of the ASAE 10, 549-555.

Cnossen, A.G., Siebenmorgen, T.J., Yang, W., 2002. The glass transition temperature concept in rice drying and tempering: effect on drying rate. Transactions of the ASAE 45 (3), 759-766.

De Boer, J.H., 1953. The Dynamical Character of Adsorption. Clarendon Press, Oxford.

Fluck, R.C., Baird, C.D., 1980. Energy requirements for agricultural inputs. In: Agricultural Energetics. AVI Publishing Company, Inc., Westport, Connecticut, p. 87.

Guggenheim, E.A., 1966. Application of Statistical Mechanics. Clarendon Press, Oxford.

Gunasekaran, S., Thompson, T.L., 1986. Optimal energy management in grain drying. Critical Reviews in Food Science and Nutrition 25 (1), 1.

Howell Jr., T.A., Cogburn, R.R., 2004. Rough-rice storage. In: Champagne, E.T. (Ed.), Rice Chemistry and Technology, vol. 3. American Association of Cereal Chemists, Inc., St. Paul, Minnesota, USA, p. 269.

Iglesias, H.A., Chirife, J., 1976. Isosteric heat of water vapour sorption on dehydrated foods: Part 1 . Analysis of the differential heat curves. Lebensmittel-Wissenchaft \& Technologie 9, 116 .

Iguaz, A., Vírseda, P., 2007. Moisture desorption isotherms of rough rice at high temperatures. Journal of Food Engineering 79 (3), 794-802.

Jayas, D.S., Mazza, G., 1993. Comparison of three-parameter equations for the description of adsorption data of oats. Transactions of the ASAE 36, 119125.

Johnson, H.K., Dale, A.C., 1954. Heat required to vaporize moisture. Agricultural Engineering 35, 705-714.

Kasmaprapruet, S., Paengjuntuek, W., Saikhwan, P., Phungrassami, H., 2009. Life cycle assessment of milled rice production: case study in Thailand. European Journal of Scientific Research 30 (2), 195-203.

Kechaou, N., Maalej, M., 1999. Desorption isotherms of imported banana. Application of the GAB theory. Drying Technology 17 (6), 1201-1213.

McLaughlin, C.P., Magee, T.R.A., 1998. The determination of sorption isotherm and the isosteric heats of sorption for potatoes. Journal of Food Engineering 35 (3) 267-280.

McMinn, W.A.M., Magee, T.R.A., 2003. Thermodynamic properties of moisture sorption of potato. Journal of Food Engineering 60 (2), 157-165

Mulet, A., García-Reverter, J., Sanjuán, R., Bon, J., 1999. Sorption isosteric heat determination by thermal analysis and sorption isotherms. Journal of Food Science 64 (1), 64-68.

Okos, M.R., Narsimhan, G., Singh, R.K., Weitnauer, A.C., 1992. Food Dehydration Handbook of Food Engineering. Marcel Dekker, New York.

Ondier, G.O., Siebenmorgen, T.J., Mauromoustakos, A., 2010. Equilibrium moisture contents of rough rice dried using high temperature, fluidized-bed conditions. Transactions of the ASABE 53 (1), 1667-1672.

Ondier, G.O., Siebenmorgen, T.J., Bautista, R.C., Mauromoustakos, A., 2011. Equilibrium moisture contents of pureline, hybrid and parboiled rice. Transactions of ASABE 53 (3), 1007-1013.

Othmer, D.F., 1940. Correlating vapor pressure and latent heat data. Industrial and Engineering Chemistry 32 (6), 841-856.

Perry, R.H., Chilton, C.H., 1973. Chemical Engineers' Handbook, fifth ed. McGrawHill, Inc., USA.

Pfost, H.B., Maurer, S.G., Chung, D.S., Milliken, G.A., 1976. Summarizing and reporting equilibrium moisture data for grains. ASAE Paper No. 76-3520, St. Joseph, Michigan, USA.

Rizvi, S.S.H., 2005. Thermodynamic properties of foods in dehydration. In: Rao, M.A., Rizvi, S.S.H., Datta, A.K. (Eds.), Engineering Properties of Foods, third ed. CRC Press, Boca Raton, FL, p. 239.

Siebenmorgen, T.J., Meullenet, J., 2004. Impact of drying, storage, and milling on rice quality and functionality. In: Champagne, E.T. (Ed.), Rice Chemistry and Technology, third ed. American Association of Cereal Chemists, St. Paul, MN, p. 301.

Souza, C.M. Alves de, Tertuliano, P.C., Rafull, L.Z.L., Prat, M.I.H., Robaina, A.D., 2006. Comparación de modelos matemáticos para descripción de las curvas de entalpia de vaporización de agua de diferentes productos agrícolas. In: Conferencia Científica de Ingenieria Agrícola de La Habana, 2006, Habana. $2^{\underline{a}}$ Conferencia Científica de Ingenieria Agrícola de La Habana, vol. 1, 2006, pp. 114.

Thompson, T.L., Peart, R.M., Foster, G.H., 1968. Mathematical simulation of corn drying. Transactions of the ASAE 24 (3), 582-586.

Tolaba, M.P., Peltzer, M., Enriquez, N., Pollio, M.L., 2004. Grain sorption equilibria of quinoa grains. Journal of Food Engineering 6, 365-371.

Toğrul, H., Arslan, N., 2006. Moisture sorption behaviour and thermodynamic characteristics of rice stored in a chamber under controlled humidity. Biosystems Engineering 95 (2), 181-195. 
Tsami, E., Maroulis, Z.B., Marinos-Kouris, D., Saravacos, G.D., 1990. Heat of sorption of water in dried fruits. International Journal of Food Science and Technology $25,350$.

Truong, V., Bhandari, T.H., Howes, T., 2005. Optimization of co-current spray drying process of sugar-rich foods: Part 1 . Moisture and glass transition temperature profile during drying. Journal of Food Engineering 71, 55-65.
Verma, L.R., 1994. New methods for on-the-farm rice drying: solar and biomass. In: Wayne, E.M., Wadsworth, J.I. (Eds.), Rice Science and Technology. Marcel Dekker, Inc., 270 Madison Avenue, New York, USA.

Zuritz, C.A., Singh, R.P., 1985. An equation to compute the heat of evaporation of water for rough rice during drying. Drying Technology 3 (3), 421-435. 